\title{
Design and Validation of Leadership Education Integrating Simulation and Project Based Learning
}

\author{
Tomoko Maruyama \\ Ehime University, Ehime, Japan \\ Masahiro Inoue \\ Shibaura Institute of Technology, Saitama, Japan
}

\begin{abstract}
All engineering students need to develop their important skills of leadership in project management. Many students have never been leaders in their social and school lives. A leading role is unimaginable to them and hence they cannot imagine how to achieve it. The purpose of this paper is to report a result of a new leadership education program which links a variety of simulated experiences with real actions of students in project based learning (PBL) to develop their leadership ability. The first step is for graduate students to gain knowledge in the leadership arena. Then, they utilize simulation to experience leadership actions many times. Simulation provides a safe environment in which they can try out many different approaches in taking leadership in various situations. In the next step, students as a team utilize PBL, so that the above simulated experiences can help them to actually take leadership. Students can apply trained leadership to actual projects. It is highly effective to apply conscious leadership to a project aimed at a specific goal in limited circumstances. This education repeats both of the steps above, raising leadership abilities in an upward spiral. In terms of students' evaluation of leadership education in project management, 360-degree assessments were carried out by teachers, senior, and junior students before and after the course, and authors compare their assessments thoroughly. As a result, authors are assured that students not only gained knowledge but also raised leadership abilities in their actions after this education. Six months after the time of leadership education employing simulated experiences and PBL, follow-up interviews were conducted on its effects. Authors recognized the cyclic period that students apply simulated experiences to PBL and that they seek different approaches in simulation for solving problems found in reality. This research concludes that this cycle of simulator and PBL can produce effective leadership actions.

Keywords: leadership education, simulated experience, project based learning (PBL), graduate student, engineering
\end{abstract}

\section{Introduction}

A project is defined in project management body of knowledge (PMBOK) (Project Management Institute, 2013); a series of fixed-term works in order to make a unique product, a service, or a result. Research has been

Tomoko Maruyama, Ph.D., assistant professor of philosophy, Office for Educational Planning and Research, Ehime University, Ehime, Japan.

Masahiro Inoue, Ph.D., professor of philosophy in engineering, College of Systems Engineering and Science, Shibaura Institute of Technology, Saitama, Japan.

Correspondence concerning this article should be addressed to Tomoko Maruyama, 3 Bunkyo-cho, Matsuyama, Ehime 790-8577, Japan. 
conducted on situational leadership and leaders' roles in projects previously (Tsuneo, 2006; Cao, 2011; Takekoshi, 2010). However, since each project is unique, it is hard to specify one specific leadership style that can lead a particular project to success. Hence, it is meaningful to pursue approaches of leadership which are applicable to any projects.

All engineering students need to develop their important skills of leadership in project management. Many students have never been leaders in their social and school lives. A leading role is unimaginable to them and hence they cannot even imagine actual manners to take leadership. Therefore, a conventional educational approach with lecture is not effective for students who do not have much real experience. Although a person could exert leadership of ideas through persuasive writings or making speeches, most leadership happens in an interactive context among individuals as well as group members (Komives, Lucas, \& McMahon, 2013). The purpose of this paper is to report a result of a new leadership education program which links a variety of simulated experiences with real actions of students in project based learning (PBL) to develop their leadership ability.

\section{Definition of Leadership}

In this research paper, leadership is defined as an ability to grasp emotion of team members accurately, to empathize with them, and to appropriately develop human relationships. In addition, leadership is not ability bestowed upon to a special person, but rather ability for everyone to exhibit and develop.

\section{Leadership Education That Integrates Simulation and PBL}

\section{Education That Utilizes Simulation}

Students who are lacking of experiences have huge gaps between knowledge and action. As a consequence, it is impossible for them to immediately turn knowledge into action. Therefore, authors utilized simulation as a means to bridge these gaps.

In other words, simulation allows students to effectively accumulate many simulated experiences. The simulated experiences that students acquire through repetitive practices can provide a smooth bridge to reality (Maruyama \& Inoue, 2011).

\section{Application of Simulated Experiences to PBL}

Any project has no precedent, in which case a creative solution is necessary. Members of such a project are required to have creativity and high motivation. Therefore, it is rational to facilitate an organizational operation structure, which allows leadership to be generated and function for project activities. All the characteristics of such an organizational operation structure are: a goal setting based on mission, outcome assessment, non-finite rules on actions, and rich communication among members (Hatou, 2008). By utilizing simulation, it is effective to apply simulated experiences as a leader to PBL.

\section{Educational Objective}

The composition of study/educational objectives and a lesson are shown below:

- To understand the systematic knowledge needed when implementing project activities;

- To practice skills and leadership within the technical areas of science and engineering;

- To understand one's own skills and to set up a behavioral objective.

The class consists of group exercises, such as a leadership exercise which utilizes simulation software, and lectures. Parallel to this, work linking the lesson to PBL is implemented. 


\section{Research Design}

Education and learning styles are shown in Table 1. The level of study is gradually set up in order of: (1) knowledge, (2) consciousness, (3) action, and (4) mastery.

Leadership education course consists of two stages in project management. The first step is for graduate students to gain knowledge in the leadership arena by a lecture. Then, they utilize simulation to experience leadership actions many times. Simulation provides a safe environment in which they can try out many different approaches in taking leadership in various situations. A simulation exercise has the effect of raising awareness of daily improvement and the necessity for new action as a result of self-reflection, all of which stem from the various virtual experiences.

In the next step, students as a team utilize PBL, so that the above simulated experiences can help them to actually take leadership. Students can apply trained leadership to actual projects and their leadership skills are additionally raised. It is highly effective to apply conscious leadership to a project aimed at a specific goal in limited circumstances. This education repeats both of the steps above, raising leadership abilities in an upward spiral. Based on this plan, the flow of study and education in Figure 1 was designed.

Table 1

Learning Styles Combined for Leadership Education

\begin{tabular}{lllll}
\hline & Lecture & Simulator & Project based learning \\
\hline \multicolumn{2}{l}{ Merits } & Deep knowledge & Many simulated experiences & Real experience \\
\hline \multicolumn{2}{l}{ Demerits } & Passive learning & Virtual & Not have a second chance \\
\hline \multirow{4}{*}{ Level } & 1. Know & $\mathrm{xxx}$ & $\mathrm{x}$ & \\
& 2. Conceive & $\mathrm{xx}$ & $\mathrm{xxx}$ & $\mathrm{xx}$ \\
& 3. Act & & $\mathrm{xx}$ & $\mathrm{xx}$ \\
& 4. Master & & $\mathrm{xx}$ & $\mathrm{xxx}$ \\
\hline
\end{tabular}

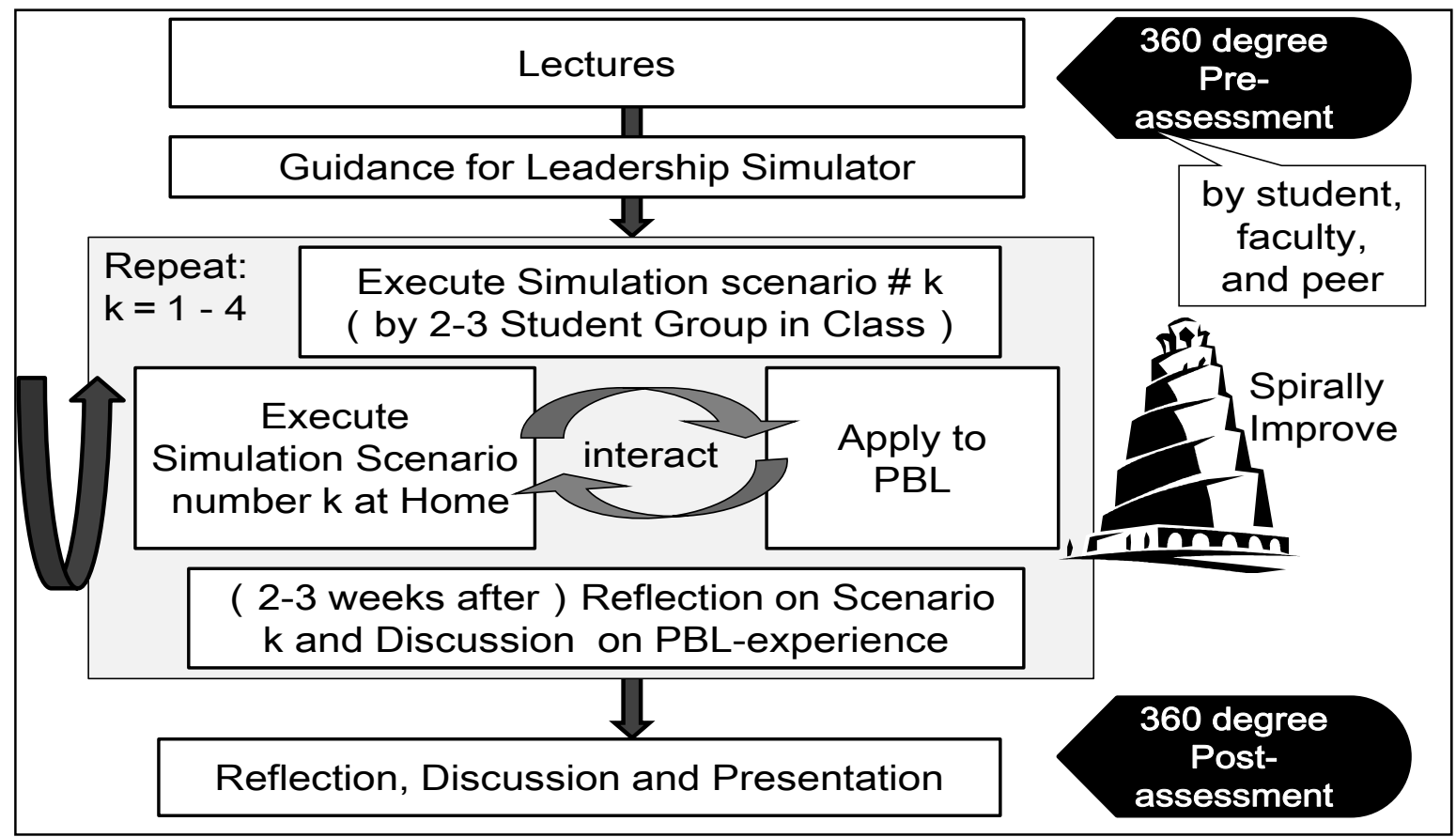

Figure 1. Architecture of leadership education. 


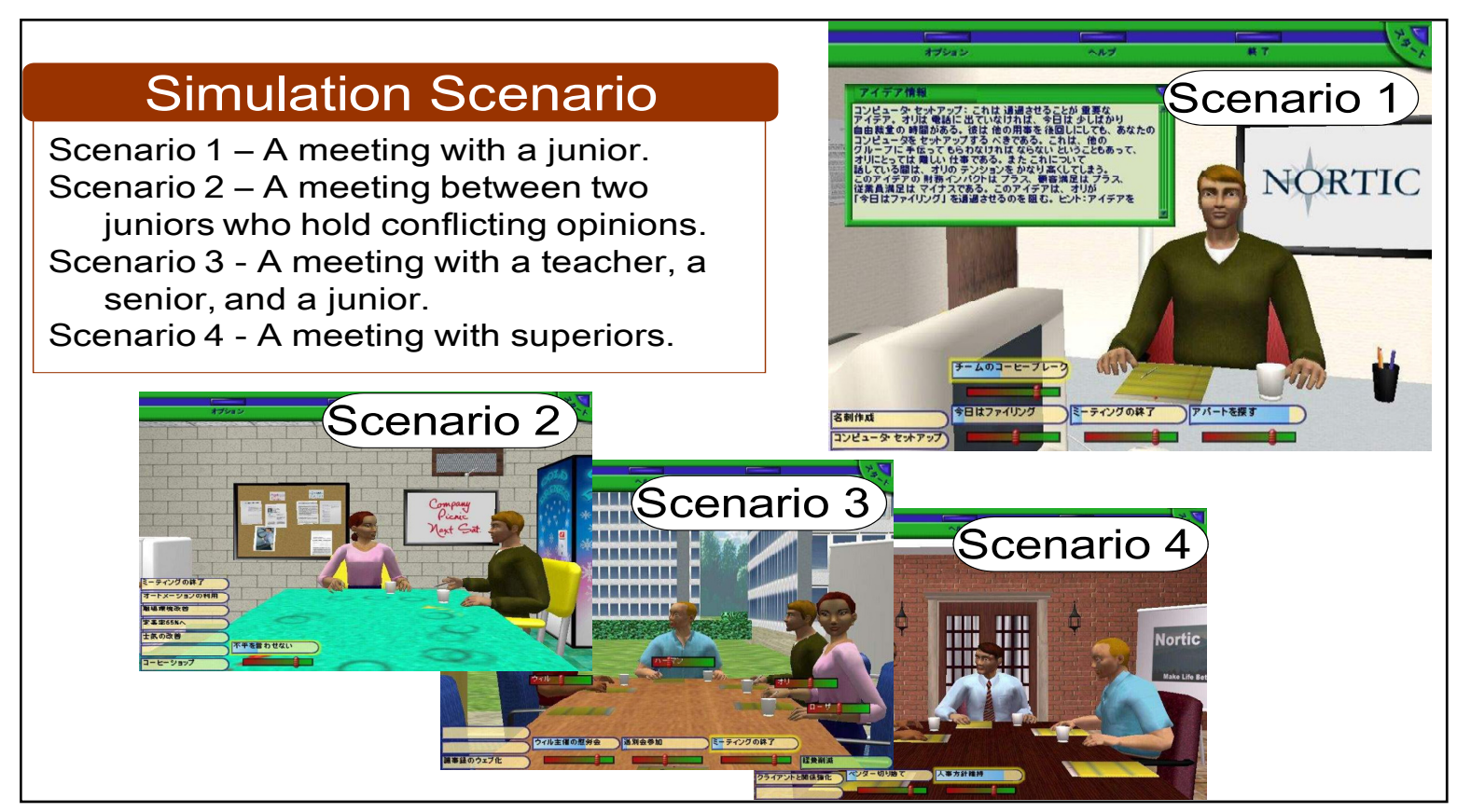

Figure 2. Leadership simulation scenario.

The virtual leader (Japanese version) of U.S. SimuLearn was used for the simulator (Inoue, Maruyama, \& Nagaya, 2014).

The following scenarios were set up for the students (Figure 2):

- Scenario $1-$ a meeting with a junior;

- Scenario 2-a meeting between two juniors who hold conflicting opinions;

- Scenario 3-a meeting with a teacher, a senior, and a junior;

- Scenario 4-a meeting with superiors.

\section{Results and Analysis}

Regarding assessment of leadership outcomes, authors conducted 360-degree assessments and a follow-up interview six months after the time of course.

\section{0-Degree Assessment}

Regarding leadership actions of the students before and after the leadership education course, authors conducted 360-degree assessments on a five-point scale to professors, senior, peer, and junior students with the questionnaire of Table 2.

Table 2

Assessment Items

\begin{tabular}{|l|l|l|}
\hline$\#$ & Items & \\
\hline 1 & I can devise my work to contribute to an activity in a project. & Work \\
\hline 2 & I can understand specific situational requirements and encourage project members to achieve their goals. & \\
\hline 3 & I can contribute to a project and achieve results through work. & \\
\hline 4 & I can share knowledge and technology with a project member positively and can strengthen a mutual relationship. & \\
\hline 5 & I can discern the cause of a problem, acquire pertinent information, and determine a solution. & Power \\
\hline 6 & I can carry out activities for the smooth progress of a project. & \\
\hline
\end{tabular}


Table 2 continued

\begin{tabular}{|l|l|l|}
\hline$\#$ & Items & \\
\hline 7 & I can coordinate socially relevant research tasks with and plant the seeds for scientific innovation. & Idea \\
\hline 8 & I can propose an idea with confidence in a timely manner. & \\
\hline 9 & I can create a plan foreseeing short- and long-term research results. & Tension \\
\hline 10 & $\begin{array}{l}\text { I can manage my and others' ability to cope with high pressure situations or rapidly changing environmental } \\
\text { conditions. }\end{array}$ & \\
\hline 11 & I can engage a project member in conversation, listen attentively and positively, and show sympathy. & \\
\hline 12 & I can raise motivation by managing a project member's level of stress. & \\
\hline
\end{tabular}

As a result of the course, scores are raised in all 12 items (Figure 3). Items 5, 9, and 10 saw especially significant increases. Application to a project seemed to develop students' problem solution and planning abilities, comparing with the poor results in application in graduate school laboratory activities (Maruyama \& Inoue, 2011). Also, the students who himself took the course showed higher score raise rate than the other evaluators (Figure 4).

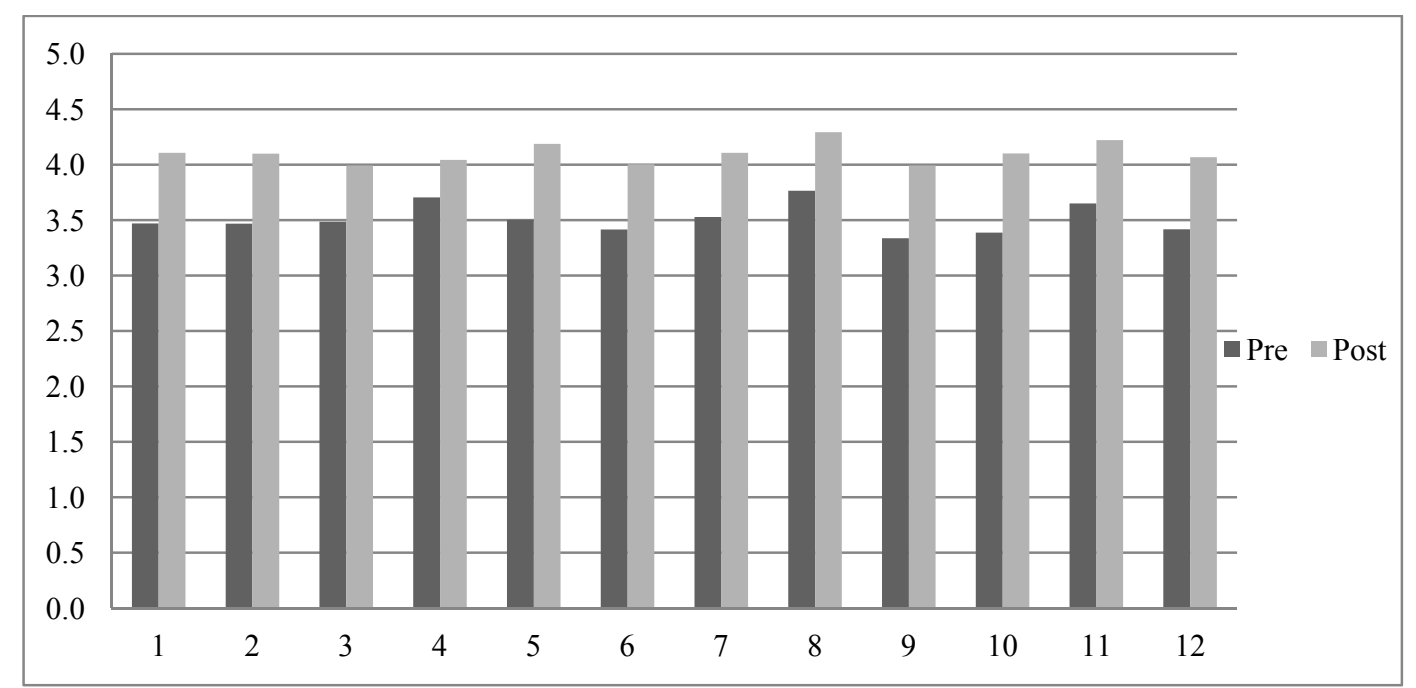

Figure 3. Improvement of student behaviour for every item in Table 2.

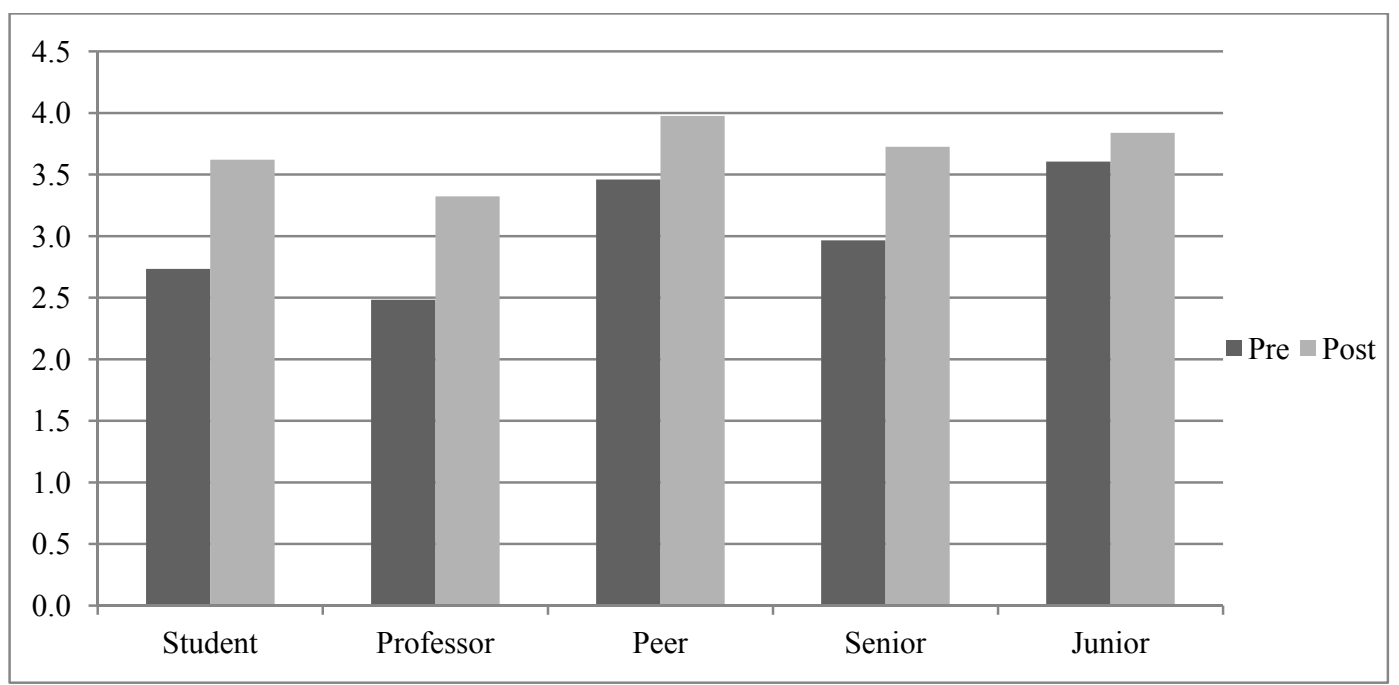

Figure 4. Improvement of student behaviour by 360-degree assessment in Table 2. 


\section{Follow-up Interview}

Six months after the time of leadership education employing simulated experiences and PBL, authors conducted follow-up interviews on its effects. They recognized the cyclic period that students apply simulated experiences to PBL and that they seek different approaches in simulation for solving problems found in reality. They made sure that this cycle of simulator and PBL can produce effective leadership actions.

Table 3

Feedback of Students Comments

\begin{tabular}{|c|c|c|}
\hline \# & \multicolumn{2}{|c|}{ Student feedback comments } \\
\hline 1 & \multirow{3}{*}{ Work } & $\begin{array}{l}\text { It is effective to apply simulated experiences to a project. Everyone has to work together to one goal and } \\
\text { therefore, each must positively give opinions and each has many chances to take leadership. With } \\
\text { simulation, I came to think of how to run a project well. }\end{array}$ \\
\hline 2 & & $\begin{array}{l}\text { I tried different approaches in simulation for solving problems found in a project. Then I applied these } \\
\text { approaches to the real project. Until the project was completed, I repeated this cycle. }\end{array}$ \\
\hline 3 & & $\begin{array}{l}\text { I had not been able to accomplish the cycle of PDCA (plan, do, check, and act) previously. However, after } \\
\text { trying simulation, my skills on running a project as a whole are raised and I was able to lead a project to } \\
\text { success. }\end{array}$ \\
\hline 4 & Power & $\begin{array}{l}\text { Since a project involves students who study different disciplines, I became aware of the difference of } \\
\text { knowledge and the degree of understanding among project student members. Therefore, when I talked } \\
\text { about the arena that other members are not familiar with, I always made sure they understood. In this } \\
\text { manner, the mutual understandings among members were enhanced. }\end{array}$ \\
\hline 5 & Idea & $\begin{array}{l}\text { With simulation training, I realized that a project could not be accomplished, if only I talked about my } \\
\text { opinion. It was important to have all the team members' opinions. }\end{array}$ \\
\hline 6 & \multirow{2}{*}{ Tension } & $\begin{array}{l}\text { I came to understand people's emotions in a project, for example, when a person who had stated his } \\
\text { opinions responded with an authoritative tone toward a comment of the others person, I felt that this } \\
\text { commentator became deflated and discouraged. }\end{array}$ \\
\hline 7 & & $\begin{array}{l}\text { When I had been a team leader in a project, I had always cared about moods of the team. With simulation, I } \\
\text { understood that I could not lead a project to success, if I only cared about these moods. I understood that the } \\
\text { strong and powerful attitude and the tension it generated were sometimes important as well. }\end{array}$ \\
\hline
\end{tabular}

\section{Conclusions}

Authors introduced leadership education which integrates simulation and PBL.

The first step is for graduate students to gain knowledge in the leadership arena. Then, they utilized simulation to experience leadership actions many times.

In the next step, students as a team utilize PBL, so that the above simulated experiences can help them to actually take leadership. Students can apply trained leadership to actual projects and their leadership skills are additionally raised. Authors validated that this cycle of simulator and PBL can produce effective leadership actions.

Finally, authors need to explore training method which can be practiced repeatedly to experience leadership actions besides the simulator.

\section{References}

Cao, J. (2011). A research for the leadership in Japanese IT business. Journal of the Society of Project Management, 13(1), 3-8. Hatou, R. (2008). Leadership Kouzouron. Tokyo: The SANNO Institute of Management.

Inoue, M., Maruyama, T., \& Nagaya, H. (2014). Project management education embedded in engineering education and research for fostering generic skills. Proceedings from Innovations 2014: World Innovations in Engineering Education and Research. iNEER, Potomac, MD, USA, 27-36.

Komives, S., Lucas, N., \& McMahon, T. (2013). Exploring leadership. San Francisco, CA: Jossey-Bass. 
Maruyama, T., \& Inoue, M. (2011). Leadership education in conjunction with real experience and pseudo experience with the use of simulator. Journal of the Society of Project Management, 13(4), 32-37.

Project Management Institute. (2013). A guide to the project management body of knowledge (PMBOK GUIDE) (5th ed.). Newtown Square, PA: Project Management Institute, Inc.

Takekoshi, S. (2010). Servant leadership for project management. Journal of the Society of Project Management, 12(1), 11-12.

Tsuneo, J. (2006). A case study of the suitable leadership style according to the project team life cycle. Journal of the Society of Project Management, 8(6), 23-28. 